OPEN ACCESS

Edited by:

Jing Ma,

Renji Hospital, Shanghai JiaoTong University School of Medicine, China

Reviewed by:

Yanyun Gu,

Shanghai Institute of Endocrine and

Metabolic Disease, Ruijin Hospital, Shanghai Jiao Tong University School

of Medicine, China

Rebecca Jane Beeken, University College London,

United Kingdom

*Correspondence:

Rachel G. Tabak

rtabak@wustl.edu

Specialty section:

This article was submitted to

Obesity,

a section of the journal Frontiers in Public Health

Received: 30 March 2018 Accepted: 31 May 2018

Published: 26 June 2018

Citation:

Tabak RG, Morshed AB, Schwarz CD and Haire-Joshu D (2018) Impact of a Healthy Weight Intervention Embedded Within a National Home Visiting Program on the Home Food Environment.

Front. Public Health 6:178. doi: 10.3389/fpubh.2018.00178

\section{Impact of a Healthy Weight Intervention Embedded Within a National Home Visiting Program on the Home Food Environment}

\author{
Rachel G. Tabak ${ }^{1,2 *}$, Alexandra B. Morshed ${ }^{1,2}$, Cynthia D. Schwarz ${ }^{1}$ and \\ Debra Haire-Joshu ${ }^{1}$ \\ ${ }^{1}$ The Brown School, Washington University in St. Louis, St. Louis, MO, United States, ${ }^{2}$ The Prevention Research Center, \\ Washington University in St. Louis, St. Louis, MO, United States
}

Purpose: To determine whether a lifestyle intervention embedded within Parents as Teachers (PAT), a national child development and parenting home visiting program, helped families make food-related home environment changes.

Design: Secondary data analysis of a stratified randomized pragmatic trial. (Trial Registration: This study is registered at www.clinicaltrials.gov NCT01567033).

Setting: Participant homes in St. Louis, Missouri.

Subjects: Women ( $n=179$ with pre-post data, of 230 with baseline) participating in standard PAT, with overweight or obesity, and at least one preschool child with BMl percentile $\geq 60 \%$.

Intervention: PAT + Healthy Eating and Active Living Taught at Home (HEALTH), embedded elements of the Diabetes Prevention Program within the standard PAT curriculum. PAT + HEALTH addressed specific behaviors that impact caloric intake (e.g., sugar-sweetened beverages), focusing on behavioral and environmental strategies. Consistent with PAT practice, the frequency, number, and focus (i.e., time spent on intervention components) of home visits were determined by the family's needs; dose structure was flexible [on average intervention: $23(S D=9)$, usual care: $13(S D=6)$ visits].

Measures: Food availability/accessibility and distractions in the home were assessed with items drawn largely from the HomeSTEAD Survey.

Analysis: Generalized estimating equations (GEEs) were used to test equality of changes between baseline and 24 months in the intervention and usual care groups.

Results: The only significant difference in the pattern of change between usual care and intervention was soda availability/accessibility $(p=0.013)$.

Conclusion: This embedded intervention successfully reduced availability/accessibility of sugar-sweetened beverages in the home. However, given the limited impact on other food-related home environment factors, future interventions could seek to more effectively intervene on all aspects of the home environment.

Keywords: home environment, food availability, eating distractions, obesity intervention, research translation 


\section{INTRODUCTION}

Obesity is prevalent in the United States and worldwide $(1,2)$, and is associated with diabetes and other acute and chronic conditions (2). Healthy eating behaviors can help reduce obesity and the risk of associated negative conditions (3). It is important therefore to develop strategies that are easy to communicate to individuals and to address modifiable factors, which can be delivered with broad reach through organizations with existing intervention delivery infrastructure.

Research on children and youth has indicated that the home environment and meal practices have important associations with dietary behaviors (4-10). This includes negative associations between availability of unhealthy food choices, and intake of these foods $(8,9,11-13)$. For example, a review by Verloigne et al. found a positive relationship between consumption of soft drinks and availability of these beverages at home (12). While this research in adults has been limited, some studies have found associations between food available in the home and weight and dietary behaviors, particularly for women (14-16). For example Wansink et al. (17), found that normal weight women were more likely to store soft drinks out of sight than obese women (17). However, this research has primarily drawn from observational studies, making it difficult to determine the direction of the associations.

Further studies have explored the associations between distraction during meals, such as TV and other technology, unhealthy eating behaviors (18-23), and obesity (24, 25). Most research has been in children and adolescents (19, 20, 22, 23), and has focused on associations with eating behaviors rather than obesity. While associations with weight status have been mixed (24-27), reducing the number of meals eaten with the TV on has been suggested as an important intervention target (28).

Based on the evidence of associations and the role of the home environment in influencing behavior in ecological models (29), home environment modifications to facilitate healthy habits could be intervention targets (14). Examples of such modifications include storing sugar-sweetened beverages so they are out of site and difficult to access. To inform intervention efforts, this study aimed to determine whether an intervention targeting the home environment was successful in helping families make food-related home environment changes.

\section{MATERIAL AND METHODS}

\section{Design}

The data for this study are drawn from a pragmatic trial promoting lifestyle change to prevent weight gain in women (30), implemented within Parents as Teachers (PAT) affiliated programs located across eight St. Louis, Missouri regions (31), which has been described elsewhere (32). PAT is a national home visiting program that promotes school readiness through optimal early development, learning, and health in young children by supporting and engaging their parents and caregivers. The program is delivered by trained parent educators and is offered free of charge to families. Stratified random sampling was used to select PAT participants within each region; the number of participants selected per region was proportional to region size.

Data were collected at baseline, 12- and 24-month follow-up. Participants received a $\$ 50$ gift card for completing the measures at each time point. This is a secondary analysis, which was not included in the original aims and hypotheses of the study. The Washington University in St. Louis Institutional Review Board approved the study protocol and all participants provided written informed consent (Trial Registration: This study is registered at www.clinicaltrials.gov NCT01567033). Additional details about the study methods, including the CONSORT diagram are provided elsewhere (32).

\section{Sample}

Participants were recruited on a rolling basis from April 2012 to September 2014. Study staff screened participants for eligibility and obtained consent on site or called mothers interested in participating. Inclusion criteria aimed to mirror real world PAT practice, thus the sample included female participants, 18-45 years of age, with a BMI $25-45 \mathrm{~kg} / \mathrm{m} 2$, with at least one preschool child at risk for overweight (BMI percentile $\geq 60 \%$ ) living in the home, who planned to continue in the PAT program for 2 years, and who were able to give informed consent. Women were excluded if they were currently pregnant or planned to become pregnant in the next 24 months, unable to speak English, currently enrolled in a weight loss program, undergoing treatment for diabetes or eating disorders, or unable to engage in a walking program.

\section{Intervention Groups}

Participants in usual care received the standard, evidence-based home visiting PAT program for parents of preschoolers that uses a strength-based, solution-focused model (33). Intervention participants received PAT + Healthy Eating and Active Living Taught at Home (HEALTH) [(32) has additional detail including a full description of the lesson topics and objectives (32)], which adapted and embedded the Diabetes Prevention Program lifestyle intervention (34) within the standard PAT curriculum. Incorporation of healthy weight content into the curriculum was guided by Social Cognitive Theory and focused on core behavior change constructs addressing intrapersonal influences (e.g., constructs of self-assessment, reinforcement), interpersonal influences (e.g., observational learning/parental modeling), and influences of the home environment (e.g., food access, TV with meals) (35). Based on formative work, the intervention was simplified to address very specific highrisk behaviors that impact the caloric intake of mothers of young children with significant time constraints. This included a focus on behavioral and environmental strategies such as limiting intake of sugar sweetened beverages. Other behavioral strategies included substituting fruits and vegetables for high calorie snacks, limiting portion sizes, increasing physical activity, and decreasing sedentary activity. An important component for all of these behavioral targets were strategies to modify the home environment to facilitate healthy choices, such as storing unhealthy food items out of sight and out of reach. Consistent with PAT practice, the frequency and number of 
visits were determined by the family's needs and preferences as was the focus and time spent on each intervention component, therefore the dose structure for the intervention is flexible.

Parent educators with PAT experience and certified on the usual care curriculum $[N=9$; mean age 44 years (range 29-67); $67 \%$ with a college degree] received additional training on the intervention (e.g., importance of parental lifestyle and modeling on child weight and development). Consistent with PAT training protocols, training took place over 1 day $(8 \mathrm{~h})$ and was in person. Fidelity monitoring, was conducted through lesson plan checklists on which parent educators documented content delivery and audiotaped home visits, which were reviewed by expert study staff as well as two randomly observed home visits a year for each parent educator (32).

\section{Data Collection and Measurement}

To understand the impact of the intervention beyond the primary outcome (maternal weight; results published elsewhere) (32), surveys were also administered. Measures drawn largely from the HomeSTEAD Survey were used to assess home environment characteristics hypothesized to relate to healthy weight behaviors that were targets of the intervention. Based on these hypotheses, items that mapped on to two scales [i.e., Food availability and accessibility (2 items) and Distractions (6 items)] in the framework informing the HomeSTEAD measure, both within the "Structure" category, were included $(22,23)$. Food availability and accessibility items asked parents to report whether the soda and snacks in their home were "Easily accessible and in plain sight"; "Accessible but out of sight;" or "Hidden and out of reach." The distraction items asked about the frequency the TV was on at breakfast, lunch, and dinner, the frequency the parent eats meals and snacks with their child while watching TV, and the frequency of technology (e.g., cell phone) use during family meals. Full item wording is available in the Supplementary Table. Research staff measured participants' height and weight in accordance with NHANES procedures (36). Sociodemographic measures (such as: age, marital status, number of children, and monthly income) were assessed by survey.

\section{Analysis}

Baseline characteristics were compared for the intervention and usual care participants included in the analysis (i.e., those with data at 12 and/or 24 months; repeated measures analysis allows for inclusion of data from participants reporting at only 12 months, only 24 months, or both 12 and 24 months) by unpaired $t$-test (for normally distributed continuous variables), Wilcoxon's test (for ordinal variables), or chi-square test (for binary variables).

Generalized estimating equations (GEEs) using a binomial distribution, logit link function, and exchangeable correlation structure (binary outcomes) or multinomial probability distribution, cumulative logit link function, and independent correlation structure (ordinal outcomes) were employed to test hypotheses regarding equality of changes over time, and included: treatment group, timepoint, and group by timepoint interaction. For outcomes with a significant interaction term, which was this study's main statistic of interest and would indicate a difference in change over time between groups, statistical contrasts within the GEE were used. These contrasts tested null hypothesis that changes between two timepoints in the usual care group were equal to corresponding changes in the intervention group. Analyses were conducted using the Statistical Analysis Systems (SAS) version 9.4 (SAS Institute, Care, NC, USA).

\section{RESULTS}

Of the 230 participants who completed the baseline assessment, 179 (78\%) completed a 12- and/or 24-month follow-up assessment. One hundred seventy-three (75\%) participants completed a 12-month follow-up, and 156 (68\%) completed a follow-up at 24 months. Most of the women in the sample were currently married (61\%). The mean age of the racially/ethnically (59\% white, 32\% African American or black, 7\% other), and economically diverse $(51 \%$ receiving WIC or other program assistance) participants who completed the study was 32 (SD 6) years. As shown in Table 1, most participants (63\%) had class I or class II obesity, while $20 \%$ were overweight and $18 \%$ had class III obesity. There were no significant differences between usual care or intervention participants at baseline, with one exception: intervention participants were generally less educated than participants in the usual care group (Table 1). On average, participants in the intervention group completed 23 (SD 9) home visits over 24 months, and those in the usual care group completed 13 (SD 6); the average length of visits for both groups was $63 \mathrm{~min}$ (SD 11).

Table 2 indicates that the home environment factor for which the interaction between intervention group and time was significant was availability of soda in the home. This indicates there was a significant difference in the pattern of change in soda availability between the usual care and intervention groups. The contrast analysis indicated that the change from baseline to 12 months $(p=0.013)$ and the change from baseline to 24 months $(p=0.003$ ) were significantly different between the usual care and intervention groups, but the change from 12 to 24 months did not differ significantly $(p=0.423)$. At baseline, $28 \%$ of participants in the usual care group indicated soda in their home was easily accessible and in plain sight, $50 \%$ indicated soda was accessible but out of sight, and $23 \%$ indicated the soda in their home was hidden and out of reach. Soda availability in this group changed little over the two time periods. However, in the intervention group, 35, 42, and $23 \%$ of participants reported soda in their home was easily accessible and in plain sight, accessible but out of sight, and hidden and out of reach, respectively, at baseline; this had improved to 13,36 , and $52 \%$ at 12 months, and to 14,44 , and $42 \%$ at 24 months.

Among the distraction items, there were no significant differences between the usual care and intervention groups in the pattern of change over the study period. 
TABLE 1 | Baseline characteristics for participants enrolled in the usual care and intervention groups of the intervention embedded in parents as teachers, who provided follow-up data at any timepoint (12 and/or 24 months).

\begin{tabular}{|c|c|c|c|}
\hline & \multirow{2}{*}{$\begin{array}{l}\text { Total cohort } \\
\text { (No. = 179) }\end{array}$} & \multicolumn{2}{|c|}{ By treatment group } \\
\hline & & $\begin{array}{l}\text { Usual care } \\
\text { (No. = 97) }\end{array}$ & $\begin{array}{c}\text { Intervention } \\
\text { (No. = 82) }\end{array}$ \\
\hline \multicolumn{4}{|l|}{ VARIABLES } \\
\hline Age (year), mean (SD) & $32(6)$ & $33(5)$ & $32(6)$ \\
\hline \multicolumn{4}{|l|}{ RACE, NO. (\%) } \\
\hline Black or African American & $57(32 \%)$ & $30(31 \%)$ & $27(33 \%)$ \\
\hline White & $105(59 \%)$ & $59(61 \%)$ & $46(56 \%)$ \\
\hline Other & $13(7 \%)$ & $8(8 \%)$ & $5(6 \%)$ \\
\hline Unknown, not reporting race & $4(2 \%)$ & $0(0 \%)$ & $4(5 \%)$ \\
\hline \multicolumn{4}{|c|}{ HIGHEST GRADE OF SCHOOL COMPLETED, NO. (\%) } \\
\hline Some high school, high school graduate & $25(14 \%)$ & $10(10 \%)$ & 15(19\%) \\
\hline Some college/technical/vocational school & $65(37 \%)$ & $33(34 \%)$ & $32(40 \%)$ \\
\hline College or university graduate & $56(31 \%)$ & $34(35 \%)$ & $22(27 \%)$ \\
\hline Graduate or professional school & $32(18 \%)$ & $20(21 \%)$ & $12(15 \%)$ \\
\hline Presently married, No. (\%) & $109(61 \%)$ & $59(61 \%)$ & $50(61 \%)$ \\
\hline \multicolumn{4}{|c|}{ ANNUAL HOUSEHOLD INCOME FROM ALL SOURCES, NO. (\%) } \\
\hline Under $\$ 30,000$ & $66(39 \%)$ & $36(38 \%)$ & $30(40 \%)$ \\
\hline$\$ 30,000-\$ 74,999$ & $62(36 \%)$ & $34(36 \%)$ & 28(37\%) \\
\hline$\$ 75,000$ - Over $\$ 100,000$ & $42(25 \%)$ & $25(26 \%)$ & $17(23 \%)$ \\
\hline WIC or other program assistance, No. (\%) & $89(51 \%)$ & $43(46 \%)$ & $46(58 \%)$ \\
\hline Weight (kg), mean (SD) & $93(15)$ & $93(15)$ & $93(16)$ \\
\hline $\mathrm{BMI}\left(\mathrm{kg} / \mathrm{m}^{2}\right)$, mean $(\mathrm{SD})$ & $34.4(5.2)$ & $34.5(5.2)$ & $34.4(5.3)$ \\
\hline \multicolumn{4}{|l|}{ OBESITY CATEGORY, NO. (\%) } \\
\hline Overweight (BMI 25.0-29.9) & $35(20 \%)$ & $19(20 \%)$ & $16(20 \%)$ \\
\hline Obese I (BMI 30.0-34.9) & $68(38 \%)$ & $35(36 \%)$ & $33(40 \%)$ \\
\hline Obese II (BMI 35.0-39.9) & 44 (25\%) & $28(29 \%)$ & $16(20 \%)$ \\
\hline Obese III (BMI $\geq 25.0)$ & 32 (18\%) & $15(15 \%)$ & $17(21 \%)$ \\
\hline
\end{tabular}

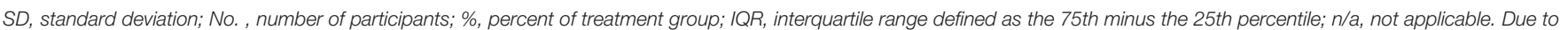
missing data, sample sizes may vary across variables.

\section{DISCUSSION}

Our findings demonstrate the impact of the HEALTH intervention on an important home environment target. Intervention group participants created a home environment with less easily accessible soda over 12 and 24 months of followup, while soda access in the homes of usual care participants did not change. This is particularly important given the previously documented benefit of the intervention on intake of added sugars and added sugars from sugar sweetened beverages as well as body weight and body mass index (32). However, HEALTH's impact was observed for only one of the home environment measures targeted.

Availability and accessibility of soda in the home was the only home environment factor impacted by HEALTH, which may be because reducing sugar-sweetened beverage intake was an important focus of the intervention; this is also a specific, measureable behavior, which may have been easier for parent educators to promote with their families (32). Embedding HEALTH within the existing, reimbursable home visits provided by PAT facilitates changes to the home environment, as parent educators work with a family in their home. This gives the educator an understanding of the family's context and can help the mother make changes to her home environment to facilitate dietary behavior changes. One such change is encouraging the mother to remove cues to drink sugar-sweetened beverages such as storage of the beverage in a place that is easily accessible or soda that is in plain sight.

Another advantage to embedding HEALTH within PAT is the ability to interact with the family over a number of visits for a sustained period of time. While 23 visits over 2 years may seem intensive, this is only 10 additional visits over 2 years more than the 13 visits usual care PAT families received. The 23 visits fit within PAT's reimbursable visit structure, which allows for additional visits for families with at least two high needs characteristics (e.g., low educational attainment, low income, parent or child with disabilities/chronic health condition, recent immigrant family, parent with mental illness, and unstable housing) (37). This allows the visit structure and content to 


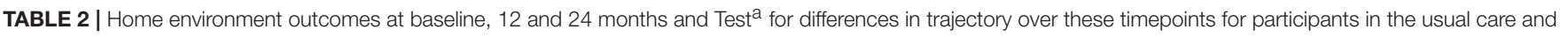
intervention groups of the HEALTH intervention embedded in parents as teachers.

\begin{tabular}{|c|c|c|c|c|c|}
\hline \multicolumn{2}{|c|}{ Outcome measures } & \multirow{2}{*}{$\begin{array}{c}\text { Baseline } \\
n(\%)\end{array}$} & \multirow{2}{*}{$\begin{array}{c}12 \text { month } \\
n(\%)\end{array}$} & \multirow{2}{*}{$\begin{array}{c}24 \text { month } \\
n(\%)\end{array}$} & \multirow[t]{2}{*}{$p$-value ${ }^{b}$} \\
\hline \multicolumn{2}{|l|}{ DISTRACTION } & & & & \\
\hline \multirow[t]{6}{*}{ TV on at Breakfast? } & Usual Care & & & & \\
\hline & Never/Rarely & $65(67.7)$ & 65 (69.9) & $63(75.0)$ & \\
\hline & Sometimes/Often/Always & $31(32.3)$ & $28(30.1)$ & $21(25.0)$ & \\
\hline & Intervention & & & & \\
\hline & Never/Rarely & $57(71.3)$ & $59(77.6)$ & $54(77.1)$ & \\
\hline & Sometimes/Often/Always & $23(28.8)$ & $17(22.4)$ & $16(22.9)$ & 0.748 \\
\hline \multirow[t]{6}{*}{ TV on at Lunch? } & Usual Care & & & & \\
\hline & Never/Rarely & $37(50.0)$ & $39(55.7)$ & $44(63.8)$ & \\
\hline & Sometimes/Often/Always & $37(50.0)$ & $31(44.3)$ & 25 (36.2) & \\
\hline & Intervention & & & & \\
\hline & Never/Rarely & $36(64.3)$ & $42(77.8)$ & $34(69.4)$ & \\
\hline & Sometimes/Often/Always & $20(35.7)$ & $12(22.2)$ & $15(30.6)$ & 0.203 \\
\hline \multirow[t]{6}{*}{ TV on at Dinner? } & Usual Care & & & & \\
\hline & Never/Rarely & $36(37.5)$ & $40(43.5)$ & 45 (53.6) & \\
\hline & Sometimes/Often/Always & $60(62.5)$ & $52(56.5)$ & $39(46.4)$ & \\
\hline & Intervention & & & & \\
\hline & Never/Rarely & $36(45.0)$ & $38(50.0)$ & $35(50.0)$ & \\
\hline & Sometimes/Often/Always & $44(55.0)$ & $38(50.0)$ & $35(50.0)$ & 0.235 \\
\hline \multirow[t]{6}{*}{ Eat dinner in front of the TV with your child? } & Usual Care & & & & \\
\hline & Never/Rarely & $50(52.1)$ & $60(64.5)$ & $54(65.1)$ & \\
\hline & Sometimes/Often/Always & $46(47.9)$ & $33(35.5)$ & $29(34.9)$ & \\
\hline & Intervention & & & & \\
\hline & Never/Rarely & $50(63.3)$ & $49(64.5)$ & $52(74.3)$ & \\
\hline & Sometimes/Often/Always & $29(36.7)$ & 27 (35.5) & $18(25.7)$ & 0.313 \\
\hline \multirow[t]{6}{*}{ Eat snacks with your child while watching TV? } & Usual Care & & & & \\
\hline & Never/Rarely & $30(31.3)$ & $32(34.4)$ & $24(28.6)$ & \\
\hline & Sometimes/Often/Always & $66(68.8)$ & $61(65.6)$ & $60(71.4)$ & \\
\hline & Intervention & & & & \\
\hline & Never/Rarely & $30(38.0)$ & $36(47.4)$ & $39(55.7)$ & \\
\hline & Sometimes/Often/Always & $49(62.0)$ & $40(52.6)$ & $31(44.3)$ & 0.074 \\
\hline \multirow[t]{6}{*}{ Cell phones, etc. during family meals? } & Usual Care & & & & \\
\hline & Never/Rarely & $61(64.2)$ & $60(65.9)$ & $56(68.3)$ & \\
\hline & Sometimes/Often/Always & $34(35.8)$ & $31(34.1)$ & $26(31.7)$ & \\
\hline & Intervention & & & & \\
\hline & Never/Rarely & $52(65.0)$ & $52(69.3)$ & $50(71.4)$ & \\
\hline & Sometimes/Often/Always & $28(35.0)$ & $23(30.7)$ & $20(28.6)$ & 0.938 \\
\hline \multicolumn{6}{|l|}{ FOOD AVAILABILITY AND ACCESSIBILITY } \\
\hline \multirow[t]{8}{*}{ I have soda at home that is: } & Usual Care & & & & \\
\hline & Easily accessible and in plain sight & $22(27.5)$ & $22(27.9)$ & $18(25.7)$ & \\
\hline & Accessible but out of sight & $40(50.0)$ & $33(41.8)$ & $33(47.1)$ & \\
\hline & Hidden and out of reach & $18(22.5)$ & $24(30.4)$ & $19(27.1)$ & \\
\hline & Intervention & & & & \\
\hline & Easily accessible and in plain sight & $23(34.9)$ & $8(12.9)$ & $8(13.6)$ & \\
\hline & Accessible but out of sight & $28(42.4)$ & $22(35.5)$ & $26(44.1)$ & \\
\hline & Hidden and out of reach & $15(22.7)$ & $32(51.6)$ & $25(42.4)$ & 0.013 \\
\hline
\end{tabular}




\begin{tabular}{|c|c|c|c|c|c|}
\hline \multicolumn{2}{|c|}{ Outcome measures } & \multirow{2}{*}{$\begin{array}{l}\text { Baseline } \\
n(\%)\end{array}$} & \multirow{2}{*}{$\begin{array}{l}12 \text { month } \\
n(\%)\end{array}$} & \multirow{2}{*}{$\begin{array}{c}24 \text { month } \\
n(\%)\end{array}$} & \multirow[t]{2}{*}{$p$-value ${ }^{b}$} \\
\hline \multirow{8}{*}{$\begin{array}{l}\text { I have sweet or salty snack foods at home } \\
\text { that is: }\end{array}$} & Usual Care & & & & \\
\hline & Easily accessible and in plain sight & $25(26.3)$ & $21(23.3)$ & $19(23.5)$ & \\
\hline & Accessible but out of sight & $53(55.8)$ & $40(44.4)$ & $41(50.6)$ & \\
\hline & Hidden and out of reach & $17(17.9)$ & 29 (32.2) & 21 (25.9) & \\
\hline & Intervention & & & & \\
\hline & Easily accessible and in plain sight & $23(29.5)$ & $12(16.7)$ & $12(17.9)$ & \\
\hline & Accessible but out of sight & $42(53.9)$ & $43(59.7)$ & $35(52.2)$ & \\
\hline & Hidden and out of reach & $13(16.7)$ & 17 (23.6) & 20 (29.9) & 0.542 \\
\hline
\end{tabular}

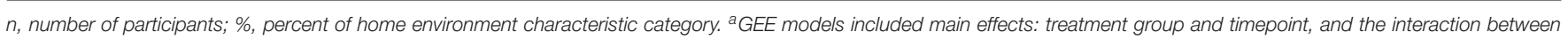
treatment group and timepoint. ${ }^{b} p$-values presented are for the interaction term in the GEE model. Bold values indicates $p<0.05$.

be tailored to the family's needs, which may require additional contact to solidify behavior change over time.

This study also informs interventions targeting other environmental changes associated with distractions (e.g., TV and eating) (38). Several studies have documented the relationship between TV and caloric intake or obesity (39-41), with some studies suggesting the impact of parents limiting TV exposure in young children (38) and removal of TVs from child bedrooms (42). However there is limited evidence of the impact of strategies to reduce family TV watching (43), particularly during mealtimes (38). One study of a home environment intervention found improvements in meals eaten in front of the TV as well as number of servings of salty/fatty snacks available in the home; this study was not limited to parents with overweight and obesity [mean (standard deviation) BMI at baseline: intervention: 29.0 (7.43); control: 28.98 (5.40)], suggesting there may be differences in responsiveness to interventions based on initial weight status (44). Our data suggest interventions requiring TV limits for multiple family members do not respond to interventions primarily targeting the primary caregiver. Additional research may be needed to identify and test more comprehensive family based strategies to promote environmental change and impact.

Other intervention studies have targeted changes to the home environment as a way to promote behavior change $(14,45)$. Gorin et al. (14) found that an intervention which included a behavioral component as well as a home environment focused intervention had benefits on the home environment as well as a stronger impact on weight loss at 6 months compared with a group that received only the behavioral component. Differences in the food environment and weight were no longer present at the 18 month follow up in the total sample, but the weight outcomes were persistent among women (15). While only one home environment factor was significantly impacted by the intervention, qualitative research has indicated even small changes can be challenging to implement (46). Further, other intervention trials have been efficacious in terms of modifying some home environment characteristics but not others $(44,45)$.

This study has limitations worth noting. Home environment data were collected by self-report, creating the possibility for social desirability bias. However, the only significant change observed in the home environment was availability of soda; if parents were reporting socially desirable answers, it might be anticipated that changes to numerous home environment characteristics would be observed. In addition, there were significant differences in objectively assessed weight between the intervention and control groups over 24 months (32). Also, while the items included mapped on to the framework informing the HomeSTEAD measure $(22,23)$, not all items from each selected scale were included. Additionally, several items that are not part of the HomSTEAD measure were included, as the HomeSTEAD tool does not include the relevant items. This may reduce the reliability and validity evidence for the environmental assessment tool. This study also included multiple comparisons, increasing the risk for Type 1 error, and in that it is an exploratory, secondary analysis, such that the original trial was not powered to detect differences in these outcomes. Finally, the study sample has limitations regarding sample size $(n=179)$ and generalizability as the population were all families from St. Louis, Missouri.

\section{CONCLUSION}

It is possible to embed an intervention to promote a healthy home environment within the reimbursable visit structure of a national home visiting program. Using targeted, specific strategies, these visits can help parents make food-related home environment changes to facilitate healthy choices. However, given the limited impact on other food-related home environment factors, future interventions could seek to more effectively intervene on all aspects of the home environment. Interventions to promote healthy eating behaviors and prevent obesity should target the home environment to reduce availability and accessibility of sugar-sweetened beverages, a relatively low cost, easily modifiable factor.

\section{DATA AVAILABILITY STATEMENT}

The datasets for this manuscript are not publicly available because of confidentiality requirements. Requests to access the datasets should be directed to Rachel Tabak (rtabak@wustl.edu). 


\section{AUTHOR CONTRIBUTIONS}

RT and AM analyzed the data. DH-J and CS designed and managed the study. All authors (RT, AM, CS, and DH-J) contributed to interpretation of results and prepared the manuscript.

\section{ACKNOWLEDGMENTS}

The authors would like to acknowledge the substantive contributions of The Parents as Teachers National Center and the parent educators that worked on this project. Funding This

\section{REFERENCES}

1. Ogden CL, Carroll MD, Kit BK, Flegal KM. Prevalence of childhood and adult obesity in the United States, 2011-2012. JAMA (2014) 311:806-14. doi: 10.1001/jama.2014.732

2. The GBD 2015 Obesity Collaborators. Health effects of overweight and obesity in 195 countries over 25 years. N Engl J Med. (2017) 377:13-27 . doi: 10.1056/NEJMoa1614362

3. Wang DD, Li Y, Chiuve SE, Hu FB, Willett WC. Improvements in US diet helped reduce disease burden and lower premature deaths, 1999,Äi2012; overall diet remains poor. Health Affairs (2015) 34:1916-22. doi: 10.1377/hlthaff.2015.0640

4. Baranowski T, Cullen KW, Nicklas T, Thompson D, Baranowski J. Are current health behavioral change models helpful in guiding prevention of weight gain efforts? Obes Res. (2003). 11(Suppl.):23S-43. doi: 10.1038/oby.2003.222

5. Glanz K, Sallis JF, Saelens BE, Frank LD. Healthy nutrition environments: concepts and measures. Am J Health Promot. (2005) 19:330-3, ii. doi: 10.4278/0890-1171-19.5.330

6. Campbell KJ, Crawford DA, Ball K. Family food environment and dietary behaviors likely to promote fatness in 5-6 year-old children. Int J Obes. (2006) 30:1272-1280. doi: 10.1038/sj.ijo.0803266

7. Foltz JL, May AL, Belay B, Nihiser AJ, Dooyema CA, Blanck HM. Population-level intervention strategies and examples for obesity prevention in children. Annu Rev Nutr. (2012) 32:391-415. doi: 10.1146/annurev-nutr-071811-150646

8. Gerards SM, Kremers SP. The role of food parenting skills and the home food environment in children's weight gain and obesity. Curr Obes Rep. (2015) 4:30-6. doi: 10.1007/s13679-015-0139-x

9. Loth KA, MacLehose RF, Larson N, Berge JM, Neumark-Sztainer D. Food availability, modeling and restriction: how are these different aspects of the family eating environment related to adolescent dietary intake? Appetite (2016) 96:80-6. doi: 10.1016/j.appet.2015.08.026

10. Ong JX, Ullah S, Magarey A, Miller J, Leslie E. Relationship between the home environment and fruit and vegetable consumption in children aged 6-12 years: a systematic review. Public Health Nutr. (2017) 20:464-80. doi: $10.1017 /$ S1368980016002883

11. Campbell KJ, Crawford DA, Salmon J, Carver A, Garnett SP, Baur LA. Associations between the home food environment and obesitypromoting eating behaviors in adolescence. Obesity (2007) 15:719-30. doi: 10.1038/oby.2007.553

12. Verloigne M, Van Lippevelde W, Maes L, Brug J, De Bourdeaudhuij I. Familyand school-based correlates of energy balance-related behaviours in 10-12year-old children: a systematic review within the ENERGY (EuropeaN Energy balance Research to prevent excessive weight Gain among Youth) project. Public Health Nutr. (2012) 15:1380-95. doi: 10.1017/S1368980011003168

13. Mazarello Paes V, Hesketh K, O’Malley C, Moore H, Summerbell C, Griffin S, et al. Determinants of sugar-sweetened beverage consumption in young children: a systematic review. Obes Rev. (2015) 16:903-13. doi: $10.1111 /$ obr.12310

14. Gorin AA, Raynor HA, Fava J, Maguire K, Robichaud E, Trautvetter J, et al. Randomized controlled trial of a comprehensive home environment-focused publication was made possible by Grant Numbers R18DK089461 and 1P30DK092950 from the NIDDK and National Heart, Lung, and Blood Institute, grant number 1T32HL130357; its contents are solely the responsibility of the authors and do not necessarily represent the official views of NIDDK.

\section{SUPPLEMENTARY MATERIAL}

The Supplementary Material for this article can be found online at: https://www.frontiersin.org/articles/10.3389/fpubh. 2018.00178/full\#supplementary-material weight-loss program for adults. Health Psychol. (2013) 32:128-37. doi: $10.1037 / \mathrm{a} 0026959$

15. Kegler MC, Alcantara I, Haardorfer R, Gazmararian JA, Ballard D, Sabbs D. The influence of home food environments on eating behaviors of overweight and obese women. J Nutr Educ Behav. (2014) 46:188-96. doi: 10.1016/j.jneb.2014.01.001

16. Monteiro CA, Moubarac, JC, Levy RB, Canella DS, da Costa Louzada ML, Cannon G. Household availability of ultra-processed foods and obesity in nineteen European countries. Public Health Nutr. (2017) 21:18-26. doi: 10.1017/S1368980017001379

17. Wansink B, Hanks AS, Kaipainen K. Slim by design: kitchen counter correlates of obesity. Health Educ Behav. (2016) 43:552-58. doi: 10.1177/1090198115610571

18. Boutelle KN, Birnbaum AS, Lytle LA, Murray DM, Story M. Associations between perceived family meal environment and parent intake of fruit, vegetables, and fat. J Nutr Educ Behav. (2003) 35:24-9. doi: 10.1016/S1499-4046(06)60323-0

19. Feldman S, Eisenberg ME, Neumark-Sztainer D, Story M. Associations between watching TV during family meals and dietary intake among adolescents. J Nutr Educ Behav. (2007) 39:257-63. doi: 10.1016/j.jneb.2007.04.181

20. Andaya AA, Arredondo EM, Alcaraz JE, Lindsay SP, Elder JP. The association between family meals, TV viewing during meals, and fruit, vegetables, soda, and chips intake among Latino children. J Nutr Educ Behav. (2011) 43:308-15. doi: 10.1016/j.jneb.2009.11.005

21. Hartman TJ, Haardorfer R, Whitaker LL, Addison A, Zlotorzynska M, Gazmararian JA, et al. Dietary and behavioral factors associated with diet quality among low-income overweight and obese African American women. J Am Coll Nutr. (2015) 34:416-424. doi: 10.1080/07315724.2014.9 82305

22. Vaughn AE, Ward DS, Fisher JO, Faith MS, Hughes SO, Kremers SP, et al. Fundamental constructs in food parenting practices: a content map to guide future research. Nutr Rev. (2016) 74:98-117. doi: 10.1093/nutrit/ nuv061

23. Vaughn AE, Dearth-Wesley T, Tabak RG, Bryant M, Ward DS. Development of a comprehensive assessment of food parenting practices: the home self-administered tool for environmental assessment of activity and diet family food practices survey. J Acad Nutr Diet. (2017) 117:214-27. doi: 10.1016/j.jand.2016.07.021

24. Granner ML, Mburia-Mwalili A. Correlates of television viewing among African American and Caucasian women. Women Health (2010) 50:783-94. doi: 10.1080/03630242.2010.533090

25. Tumin R, Anderson SE. Television, home-cooked meals, and family meal frequency: associations with adult obesity. J Acad Nutr Diet. (2017) 117:93745. doi: 10.1016/j.jand.2017.01.009

26. Emery CF, Olson KL, Lee VS, Habash DL, Nasar JL, Bodine A. Home environment and psychosocial predictors of obesity status among community-residing men and women. Int J Obes. (2015) 39:1401-7. doi: 10.1038/ijo.2015.70

27. Trofholz AC, Tate AD, Miner MH, Berge JM. Associations between TV viewing at family meals and the emotional atmosphere of the meal, meal 
healthfulness, child dietary intake, and child weight status. Appetite (2017) 108:361-6. doi: 10.1016/j.appet.2016.10.018

28. Golan M. Fifteen years of the Family Eating and Activity Habits Questionnaire (FEAHQ): an update and review. Pediatr Obes. (2014) 9:92101. doi: 10.1111/j.2047-6310.2013.00144.x

29. Story M, Kaphingst KM, Robinson-O’Brien R, Glanz K. Creating healthy food and eating environments: policy and environmental approaches. Annu Rev Public Health (2008) 29:253-272. doi: 10.1146/annurev.publhealth.29.020907.090926

30. Ford I, Norrie J. Pragmatic trials. N Engl J Med. (2016) 375:454-463. doi: 10.1056/NEJMra1510059

31. Parents As Teachers (2016). Annual Report 2015-2016.

32. Haire-Joshu D, Schwarz CD, Steger-May K, Lapka C, Schechtman K, Brownson RC, et al. A randomized trial of weight change in a national home visiting program. Am J Prev Med. (2018) 54:341-51. doi: 10.1016/j.amepre.2017.12.012

33. Parents As Teachers (2015). Annual Report 2014-2015.

34. Diabetes Prevention Program Research G, Knowler WC, Fowler SE, Hamman RF, Christophi CA, Hoffman HJ, et al. 10-year follow-up of diabetes incidence and weight loss in the Diabetes Prevention Program Outcomes Study. Lancet (2009) 374:1677-86. doi: 10.1016/S0140-6736(09)61457-4

35. Young MD, Plotnikoff RC, Collins CE, Callister R, Morgan PJ. Social cognitive theory and physical activity: a systematic review and meta-analysis. Obes Rev. (2014) 15:983-995. doi: 10.1111/obr.12225

36. CDC NHANES (2009). Center for Disease Control and Prevention. National Health and Nutrition Examiniation Survey: Anthropometry Procedures Manual. Available online at: https://www.cdc.gov/nchs/data/nhanes/nhanes_ 09_10/lab.pdf (Accessed June 16, 2017).

37. Parents as Teachers National Center PAT Quality Assurance Guidelines. Available online at: http://www.parentsasteachers.org/images/stories/QA_ guidelines_May_2016.pdf (2016) (Accessed September 26, 2016).

38. Wen LM, Baur LA, Simpson JM, Xu H, Hayes AJ, Hardy LL, et al. Sustainability of effects of an early childhood obesity prevention trial over time: a further 3-year follow-up of the healthy beginnings trial. JAMA Pediatr. (2015) 169:543-51. doi: 10.1001/jamapediatrics.2015.0258

39. Cameron JD, Maras D, Sigal RJ, Kenny GP, Borghese MM, Chaput JP, et al. The mediating role of energy intake on the relationship between screen time behaviour and body mass index in adolescents with obesity: the HEARTY study. Appetite (2016) 107:437-44. doi: 10.1016/j.appet.2016. 08.101
40. Avery A, Anderson C, McCullough F. Associations between children's diet quality and watching television during meal or snack consumption: a systematic review. Matern Child Nutr. (2017) 13:e12428. doi: $10.1111 / \mathrm{mcn} .12428$

41. Biddle SJH, Bengoechea Garcia E, Pedisic Z, Bennie J, Vergeer I, Wiesner G. Screen time, other sedentary behaviours, and obesity risk in adults: a review of reviews. Curr Obes Rep. (2017) 6:134-47. doi: 10.1007/s13679-017-0256-9

42. Haines J, McDonald J, O’Brien A, Sherry B, Bottino CJ, Schmidt ME, et al. Healthy habits, happy homes: randomized trial to improve household routines for obesity prevention among preschool-aged children. JAMA Pediatr. (2013) 167:1072-9. doi: 10.1001/jamapediatrics.2013.2356

43. Braude L, Stevenson RJ. Watching television while eating increases energy intake. Examining the mechanisms in female participants. Appetite (2014) 76:9-16. doi: 10.1016/j.appet.2014.01.005

44. Byrd-Bredbenner C, Martin-Biggers J, Povis GA, Worobey J, Hongu N, Quick V. Promoting healthy home environments and lifestyles in families with preschool children: HomeStyles, a randomized controlled trial. Contemp Clin Trials (2017) 64:139-51. doi: 10.1016/j.cct.2017.10.012

45. Fulkerson JA, Friend S, Horning M, Flattum C, Draxten M, Neumark-Sztainer D, et al. Family home food environment and nutrition-related parent and child personal and behavioral outcomes of the Healthy Home Offerings via the Mealtime Environment (HOME) Plus program: a randomized controlled trial. J Acad Nutr Diet. (2017) 118:240-51. doi: 10.1016/j.jand.2017. 04.006

46. Eldridge JD, Devine CM, Wethington E, Aceves L, Phillips-Caesar E, Wansink $B$, et al. Environmental influences on small eating behavior change to promote weight loss among Black and Hispanic populations. Appetite (2016) 96:12937. doi: 10.1016/j.appet.2015.09.011

Conflict of Interest Statement: The authors declare that the research was conducted in the absence of any commercial or financial relationships that could be construed as a potential conflict of interest.

Copyright (๑) 2018 Tabak, Morshed, Schwarz and Haire-Joshu. This is an open-access article distributed under the terms of the Creative Commons Attribution License (CC $B Y)$. The use, distribution or reproduction in other forums is permitted, provided the original author(s) and the copyright owner are credited and that the original publication in this journal is cited, in accordance with accepted academic practice. No use, distribution or reproduction is permitted which does not comply with these terms. 